\title{
Correction to: Patient-Reported Outcomes Measures in Abdominal Cancer Surgery and Student-Led Surgical Research
}

\author{
Augusto León, MD, MSCCh, FACS ${ }^{1}$, Klaus Puschel, MD, MPH, $\mathrm{MSc}^{2}$, Augusto E. León, $\mathrm{MD}^{3}$, and \\ Francisca Honold, $\mathrm{MD}^{4}$ \\ ${ }^{1}$ Program of Cancer, Department of Surgical Oncology, Catholic University of Chile, Santiago, Chile; ${ }^{2}$ Program of Family \\ Medicine, Catholic University of Chile, Santiago, Chile; ${ }^{3}$ Resident of Radiotherapy, Instituto de Radiomedicina IRAM, \\ Diego Portales University, Santiago, Chile; ${ }^{4}$ Resident of Surgery, University of Chile, Santiago, Chile
}

CORRECTION TO: ANN SURG ONCOL (2021) 28:2941-2943

HTTPS://DOI.ORG/10.1245/S10434-021-09686-5

The article Patient-Reported Outcomes Measures in Abdominal Cancer Surgery and Student-Led Surgical Research, written by Augusto León et al., was originally published online on March 31, 2021, with Open Access under a Creative Commons Attribution (CC BY) licence
4.0. After publication in volume 28 , issue 6 , pages 2941-2943, the author(s) decided to cancel the Open Access. Therefore, the copyright of the article has been changed on August 4, 2021, to CSociety of Surgical Oncology 2021 with all rights reserved.

Publisher's Note Springer Nature remains neutral with regard to jurisdictional claims in published maps and institutional affiliations.

The original article can be found online at https://doi.org/10.1245/ s10434-021-09686-5.

(C) Society of Surgical Oncology 2021

Published Online: 13 August 2021

A. León, MD, MSCCh, FACS

e-mail: aleon84@gmail.com 